\title{
Question and Answer Sessions with Dr. René G. Mély
}

\section{Tokyo}

Chairman: Prof. Dr. Mitsuru Sawa

(Department of Ophthalmology, Nihon University

School of Medicine)

Dr. Sawa: Any questions will be invited from the audience. Please do not hesitate to speak in Japanese.

Dr. Osamu Katsumi (Tokyo): Thank you for the lecture. I practice in Tokyo and prescribe contact lenses. What kind of patients would you not prescribe this 30-day compliant lens for?

Dr. Mély: First, I would not prescribe extended-wear lenses if the patient is not compliant. It is not always easy to say which patients are reliable and which are not. Noncompliance is a problem because patients begin to wear lenses for 2 or 3 months without changing them. And secondly, I would be very careful in cases of immune deficiency.

Dr. Sawa: In a historical context, you showed us that the rate of extended lens wear differed between countries. For instance, in Sweden, the rate was high. But in Germany, the rate was about $4 \%$, which is very low. What factors affected the difference between these two countries?

Dr. Mély: This is difficult to say. One point is certain about Sweden: as in other Scandinavian countries, the first disposable extended-wear lenses were introduced very early in the eighties. The name of the lens was Danalens ${ }^{\circledR}$, a precursor of the Acuvue ${ }^{\circledR}$ lens, and it was very popular in Scandinavia. But I think the most important point is the attitude of eye care professionals who recommend them or do not. Probably in Germany, and also in France, ophthalmologists have always been very cautious about recommending extended-wear lenses.
Dr. Sawa: What is the percentage of 30-day extended wear lens users in Europe? You told us that there are about 800,000 users.

Dr. Mély: There are no studies which give us exact data. We have only data on the sales number of lenses, which gives us an estimate of the number of lens wearers. But it is very difficult to know how many people are then wearing these lenses on an extended-wear basis or just on a daily-wear basis. So, I don't have more precise data to give you.

Dr. Sawa: We are having a party after this session. Dr. Mély will accept your individual questions at the party. Thank you very much.

\section{Osaka}

\section{Chairman: Prof. Shigeru Kinoshita}

(Kyoto Prefectural University)

Dr. Kinoshita: Thank you for the very interesting lecture. I am much intrigued because I myself have no experience in the therapeutic use of these lenses. Are there any questions from the audience?

Dr. Hikaru Hamano (Osaka): Thank you very much for your very informative lecture.

The results showed that high-Dk lenses $(125$ or $175 \times$ $10^{-9}$ ) performed almost the same as the control, and the oxygen pressure under the lens or under the cornea is less than $20 \mathrm{~mm} \mathrm{Hg}$. Do you think $20 \mathrm{~mm} \mathrm{Hg}$ is enough for continuous or extended wear?

Dr. Mély: This is a difficult question. I think you know more about oxygen transmissibility measurements than I do. I have only a clinical experience with these lenses and

\begin{tabular}{ll}
\hline KARGER & (c) 2004 S. Karger AG, Basel \\
0030-3755/04/2187-0045\$21.00/0 \\
$\begin{array}{l}\text { Fax +4161306 1234 } \\
\begin{array}{l}\text { E-Mail karger@karger.ch } \\
\text { www.karger.com }\end{array}\end{array}$ & $\begin{array}{l}\text { Accessible online at: } \\
\text { www.karger.com/oph }\end{array}$
\end{tabular}


have not performed any research about the minimum oxygen requirements of the cornea. I must say that I have not seen any oxygen-related problems with high-Dk lenses in my clinic, so I think a Dk/L of $175 \times 10^{-9}$ is enough.

Dr. Motozumi Itoi (Tokyo): I suspect that these lenses are associated with a somewhat higher occurrence of mechanical complications. With respect to giant papillary conjunctivitis (GPC), these lenses seem to induce a type of GPC that has not been observed with conventional soft lenses. So, I think there is a need for modifying lens design or hardness. What is your opinion?

My second question is about keratitis due to MK infection. Different countries have different diagnostic criteria for a bacterial corneal infiltration and contact lensinduced peripheral ulceration. The reported high prevalence in Australia might be affected by the data from the group of Brian Holden. Do you think we can actually expect the reported low occurrence when we compare these silicone hydrogel lenses with daily-wear and monthly-wear contact lenses from other manufacturers?

Dr. Mély: The answer to the first part of your question is that I have not seen any typical mechanically induced GPC case in my own series of patients. I must say, however, that I do not have a large experience on long-term wear of these lenses as most of my patients were fitted for therapeutic purposes.

I am afraid I have not understood very well the second part of the question.

Dr. Itoi: The concept of a bacterial corneal infiltration has not been widely understood in Japan. The literature from overseas in the last decade shows that this concept has been established gradually. In this sense, I'm concerned if we can directly compare current and past studies. I'd like to hear your opinion.

Dr. Mély: I also have the feeling that a number of cases of so-called sterile infiltrations were referred to in past studies as bacterial keratitis. I must say however that it is quite difficult to demonstrate this retrospectively. We need more precise criteria to differentiate severe microbial keratitis from infiltrative events. Therefore in the research literature one has to look very precisely at the diagnostic criteria of keratitis utilized in order to compare conclusions from different studies.

Dr. Itoi: Let me explain why I asked this question. In various statistics of eye disorders in Japan, the data reported that so-called corneal infiltration is considered to include many cases of contact-lens-induced peripheral ulceration. When we look at international statistics related to these silicone hydrogel lenses, the data include about $5 \%$ of such cases. I asked the question because I wanted to know how we should compare the data from Japan and those from overseas.

Dr. Wakako Iwasaki (Osaka City): Shortly ago, Dr. Itoi and I attended a meeting of contact lens specialists. My impression at the meeting was that these lenses tend to cause small scratches on the cornea due to poor finish of the edges. In addition, they may form crystalline deposition at about $2 \mathrm{~mm}$ from the lens edge. According to the data presented, these lenses are not suitable to smokers because the indoor air around smokers is contaminated and the lenses absorb contaminants in air during the processes of disinfection and oxygen intake. Could you elaborate on the reason why these lenses are not suitable to smokers?

Dr. Mély: Smoking is obviously very unhealthy for all contact lens wearers. It has been proven that smoking is a risk factor for keratitis, but the mechanism is actually not known. I do not think it is related to crystalline deposition on the lens surface but I cannot give you an exact answer related to etiology.

Dr. Kiichi Ueda (Shimonoseki City): My question is related to the question from Dr. Itoi. Could you provide some more information about GPC associated with these lenses? As a matter of fact, I have a patient who was fitted with silicone hydrogel soft contact lenses at a clinic overseas. This case developed severe GPC during continuous wear. Some doctors who participated in the clinical trial of these lenses commented that they seemed to cause a somewhat high incidence of GPC. If it were the case, what is your opinion about the problems of lens material, surface treatment and design?

Dr. Mély: I don't believe that the incidence is high. I think this form of GPC is related to a mechanical factor. This is due to the high modulus of the lenses, and maybe also to lens design. These are considerations important to improve in the future.

Dr. Kinoshita: I have just a simple question for you. What do you think about the guidelines for the advantages of soft contact lenses? What team developed the guidelines?

Dr. Mély: These guidelines were developed in Germany by the two major societies of ophthalmology in our country, the BVA and the DOG.

Dr. Kinoshita: Thank you very much. It is time to end this session. Thank you for your attention.
46

Ophthalmologica 2004;218(suppl 1):45-46
Question and Answer Sessions with Dr. René G. Mély 